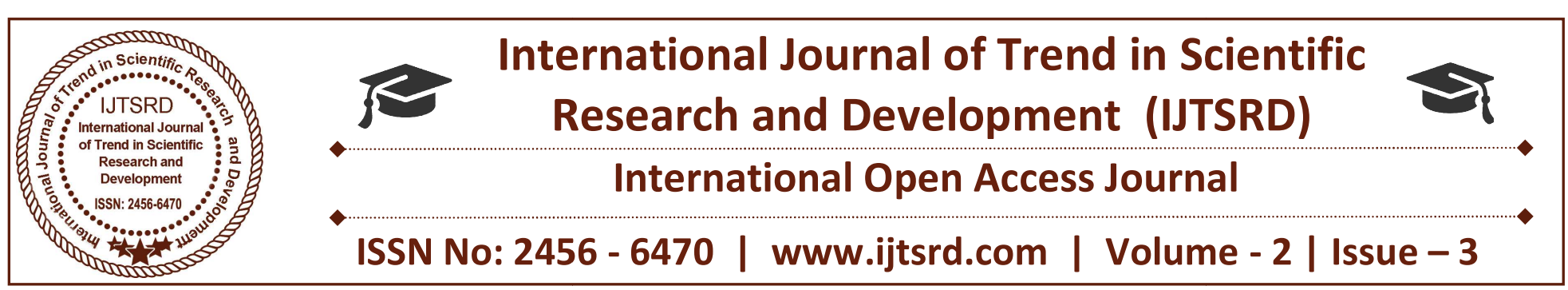

\title{
Comparative Analysis of Asset Liability and Risk Management of Selected Urban Cooperative Banks in Nagpur Region using CAMEL Model
}

\author{
Mrs. Snehal P. Joshi \\ Department of Business Management, \\ Rashtrasant Tukadoji Maharaj Nagpur University, \\ Nagpur, Maharashtra, India
}

\author{
Dr. Reeta V. Sontakay \\ Department of Commerce, C.P. \& Berar College, \\ Rashtrasant Tukadoji Maharaj Nagpur University, \\ Nagpur, Maharashtra, India
}

\section{ABSTRACT}

Banking is said to be the lifeline of any economy. Banks have to deal with many risks in day to day work. Main risks involved in banking are liquidity risk, management risk, credit risk etc. to deal with risk financial regulatory has issued some techniques and model for managing the risks. One of the models to deal with risk is CAMEL in Indian banking industry. The present study deals with the analysis of financial performance of selected Urban Co-operative Banks (UCB) in Nagpur region through CAMEL model. The analysis shows the study of UCBs for eight years. Each UCB is analyzed based on the values given in the Balance sheet for the CAMEL model. Our study shows the individual performances in comparison to the other selected UCBs of Nagpur region.

Keywords: CAMEL model, Risk Management, Asset and Liability, Banks

\section{INTRODUCTION:}

Asset Liability management (ALM) is a process of planning, organising, controlling and managing different types of risk in banks. ALM is the coordinated management of the balance sheet. It helps the banks to minimize the risk and concentrate to earn maximum profit. Banks has to face many risks in day to day life which includes Market risk, Liquidity risk, credit risk, etc. ALM is a tool to deal with this kind of risks. ALM plays a crucial role in managing the risks. ALM process rest on three pillars:
- ALM Information System.

$>$ Management Information System

$>$ Information availability, accuracy, adequacy and expediency

- ALM organization.

Structure and responsibilities

$>$ Level of top management involvement

- ALM Process.

$>$ Risk parameters

D Risk identification

ALCO (Asset Liability committee) is a decision making unit of the banks, which includes the top most employees of the bank such as CEO, Board of Directors etc. it is the responsibility of members of ALCO for the smooth running of ALM tools. [13]

\section{A. Importance of ALM}

It is said that ALM is a lifeline of any financial institutions as well as for banks. In other words ALM is back bone of any financial institutions. The proper management of ALM plays a key role for any banks and other institutions. Different models are available for the banks to ensure its progress and can keep an eye on the business of the banks. CAMEL model is very traditional method to analyze the ratios and other related financial stability of the banks. 
Financial health plays a crucial role in banking industry. Risks are the major threats to working of banks. To control this risk various measures are stated by different committees. BASEL III set the instructions for the banks which includes major banking principals i.e. capital, leverage, funding and liquidity. Universally there are four principal approaches which are used to quantify the risks. They are Gap Model, Simulation, Duration and Value at Risk method (VaR). Some techniques such as Duration analysis of ALM do not consider liquidity risk issue at all. Others are highly compatible with cash flow analysis [11]. As the business of banks has increased risks also increased. Traditional techniques of ALM also evolved to cope up with markets.

In order to cope up with the risk and to earn maximum profit with minimum risk, also to make ensure for banks how much they are adhere to standard norms CAMEL rating system was introduced. CAMEL is a conventional rating model which was first developed in 1970 by three federal banking supervisors of the U.S. The banks were evaluated on five different components under the acronym C-A-M-E-L. It consists of five main dimensions (Capital Adequacy, Assets quality, Management capability, Earning Capacity, and Liquidity) with each section having some ratios to analyze the performance of the bank. The banks were judged on five different components under the acronym C-A-M-E-L: The banks received a score of ' 1 ' (strongest) through ' 5 '(weakest) for each component of CAMEL and a final CAMEL rating representing the composite total of the component CAMEL scores as a measure of the bank's overall condition. [11]

\section{Related Work}

The on-site supervision involves an Annual Financial Inspection (AFI) of banks that is presently modeled around the CAMEL (Capital Adequacy, Asset classification, Management, Earnings appraisal, Liquidity) framework. The present CAMEL is a transaction-based examination with a matrix used for arriving at a rating of each of the CAMEL components to give a final adjusted supervisory rating for each bank. Of late, the AFI has been giving considerable importance to risk management system in banks. Based on the concerns highlighted by the AFI reports and discussions with banks, a Monitor able Action Plan (MAP) is drawn for compliance and a memorandum covering supervisory concerns from
AFI including supervisory rating is compiled for perusal of the BFS. In addition to AFI, a few need based targeted inspections and scrutinizes at the banks are also undertaken. [13]

Considerable study has done by the scholars in this field of ALM sited below in [1-10].

The paper [1], analyzes the study of 16 Iranian banks through CAMEL model. The author has chosen five indicators of CAMELS category and then all indicators are calculated for an Iranian bank and then the results are compared with average of industry. The author suggests to the bankers that they can use this CAMEL model to calculate and discuss ratios and can focus on some emergency and can cope up with crisis.

The paper [2] analyzes 58 banks in India using CAMEL model. Financial variables and financial ratios were used to carry out the study. The paper normalizes the variables of CAMEL model with respect to upper and lower bound to provide ratings to the banks.

The paper [3] analyzes the camel model for nationalized banks in India. The study elaborates the bank performance for 5 years of twenty banks. Further the paper deals with the factors of CAMEL model. The author has calculated average of each ratio. In the study the author has ranked all the banks based on the sub-parameters of each parameter. The sum of these ranks was then taken to arrive at the group average of individual banks for each parameter. Finally the composite rankings for the banks were arrived at after computing the average of these group averages. Banks were ranked in the ascending/descending order based on the individual sub-parameter.

The paper [4] analyzes the study on the soundness of the banking industry. The researchers have studied total twelve banks, (selected through some criteria). Further the scholars discussed the CAMEL model with their formulas. The authors have used average system for calculating the camel ranking. The paper concludes stating that as the trend pursue, the private banks are growing at a faster pace than public sector banks.

The paper [5] analyzes the performance of state bank group through CAMEL model for 3 years. The author has used twenty financial ratios for evaluate performance of the banks. The author has used simple arithmetic mean. One way ANOVA test has been 
International Journal of Trend in Scientific Research and Development (IJTSRD) ISSN: 2456-6470

used to determine whether there is significant difference between the CAMEL ratios. The author had done the normality check with KolmogorovSmirnov Test and Shapiro Wilk test.

The paper [6] analyzes five Indian Nationalized banks for six years using CAMEL model. The author has used statistical techniques such as percentage, average, coefficient of variation and one way ANOVA also applied in the study.

The paper [7], analyzes the performances of three types of banks, i.e. Public Sector bank, Private Sector bank and Foreign banks for study purpose. The scholars used ANOVA test for testing hypothesis. The study concludes by suggesting lower performer banks that they need to improve their performance.

The paper [8] analyzes the top ten banks of India through CAMEL model. The study shows Bank of Baorada has scored top position and Central bank is on bottom. The paper [9] analyzes the financial strength of selected banks through CAMEL model. Certain ratios are calculated under the CAMEL model and composite rankings, Average and covariance is applied to reach conclusion. The author has selected top five private banks for ten years using secondary data. After the study it is found that Axis bank is at top position and Indusland bank is at last one.

The paper [10] analyzes Scheduled Urban cooperative bank in Surat City. The author has collected the data for 10 years. The author has used the statistical techniques i.e. mean, Standard deviation and coefficient of variation.

The work cited in the papers [1-10] proves the efficiency of the CAMEL model in deciding the performance of the banks. The urban cooperative banking in the India is established to promote, support and solve the problems of the lower middle income group in the Indian society. Therefore the financial stability of the cooperative banks is indeed necessary. Hence we analyze the financial performance of selected UCBs using CAMEL model for the period 2010-2017. The components for CAMEL model are capital adequacy, asset quality, management, earnings, and liquidity. The analysis is based on secondary data through banks annual reports. For the study purpose ratios are calculated to get the rankings and at the end their composite ratings for their final ratings. Three statistical techniques i.e. mean, standard deviation and coefficient of variance are also calculated to analyze the performance of the parameters in CAMEL model.

\section{A. Scope of the study}

The scope of the study is limited to only 5 UCBs for the period of eight years. The banks which are used for the study are SHIKSHAK SAHAKARI BANK (SSB), THE SHAMRAO VITTHALRAO COOPERATIVE BANK (SVCB), THE THANE JANTA SAHAKARI BANK LTD (TJSB), THE SARASWAT CO-OPERATIVE BANK Ltd.(Saraswat), THE NAGPUR NAGRIK SAHAKARI BANK LTD (NNSB).

\section{Interpretations of Results:}

We analyze the performance of the selected UCBs using the CAMEL model. The data for the performance analysis is taken for the duration of eight years from 2010 to 2017. Each factor in the CAMEL model is calculated and analyzed for all the selected banks. We present the interpretation of the results obtained from the CAMEL model analysis as below.

\section{A. Analysis and Interpretations of Capital Adequacy (C):}

It's a bank capacity to meet the time liabilities and other risk which includes credit risk, operational risk etc. In other words it is cushion for the banks against losses it also protect its depositors and lenders. It is a specified amount which a bank has to maintain with financial regulator. As per RBI guidelines the CAR ratio has to be maintained $9 \%$ and above.

Fig 1(a) compares the capital adequacy ratio of all the selected UCBs. We see that NNSB bank outperforms as compared to the other from the year 2013 onwards. From the year 2013 onwards the Tier I and II capital of NNSB shows significant increase which contribute to the increase in the capital adequacy ratio as compared to other. We found the average CAR of NNSB for the selected durations is 15.94. The average CAR for the SSB is weighing only 7.26 in the years 2010- 2012 which lowers the performance of SSB as compared to the NNSB. The Saraswat on the other hand, maintains the CAR above $9 \%$ throughout the period of analysis.

Credit Deposit Ratio (CDR): It indicates the amount of core funds used for lending. Lower the ratio indicates lower lending as compared to deposited amount. The average CDR for the Saraswat bank is 
highest and found to be $67.48 \%$ whereas, others except NNSB maintains this ratio between 60 to $64 \%$. The CDR for NNSB in the year 2010, 2015-17 averages to value 53.14.

Advances to Total Asset ratio: It is a ratio of total advances to total assets. Higher advances indicate the aggressive policies of the bank to make profits. The Fig 1c shows the Saraswat and SVCB has aggressive policies for profit making by lending. The average values for the Saraswat bank and SVCB for this ratio are 52.26 and 55.68 respectively. The other banks believe in maintaining this average below $50 \%$.

Government Securities to total investment ratio: This ratio indicates the risk taking ability of the bank. As it is believed that the investments in government securities are at lower side of risk, this also gives the lower returns of the invested amount resulting to lower profit. NNSB and SVCB have more than $90 \%$ of investment in government securities. TJSB is slightly less than $90 \%$. On the other hand the SSB and Saraswat keeps this component of share between $75 \%$ to $77 \%$. This strategy becomes one of the driving factor of the overall profit of the bank, it can be seen from the net profit values (analyzed latter) that the SSB and Saraswat has more profit earned as compared to NNSB and SVCB.

Debt equity ratio: The parameters indicate how much of the business is financed through debt funds and how much through the equity. Higher ratio indicates the debt obligators may not be satisfied at due to lack of cash. While the lower value of this ratio indicates the advantages of the profits are not fetched by the bank. The analysis carried out on this parameter shows the maintained lower side performance of the selected banks, all below 14. The NNSB plays a safe game of maintaining the ratio throughout up to 5.16 only. However Saraswat and SSB take a little risk and maintain this ratio with an average of 13.26 and 13.11 respectively.

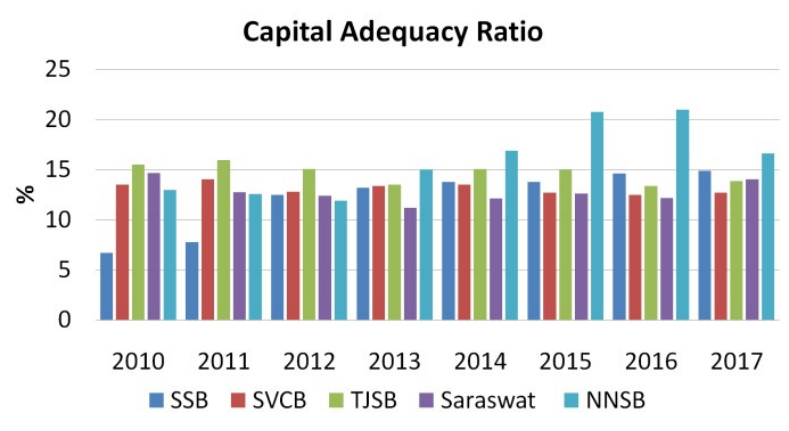

Fig: 1(a) Capital Adequacy Ratio

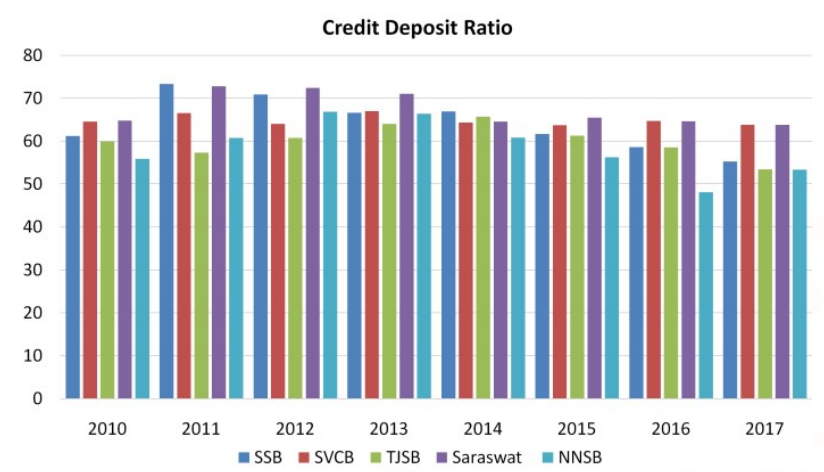

Fig: 1(b) Credit Deposit Ratio

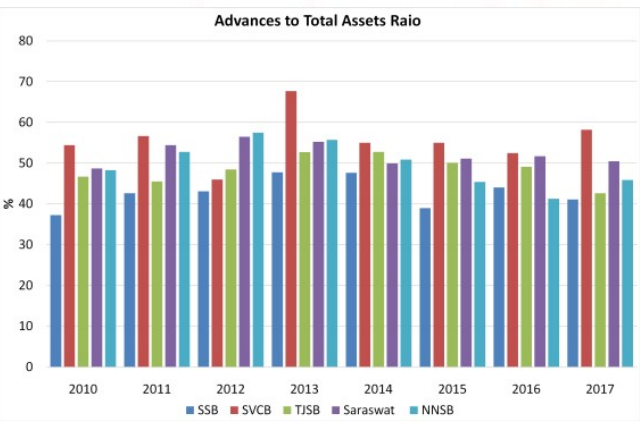

Fig: 1(c) Advances To Total Assets Ratio

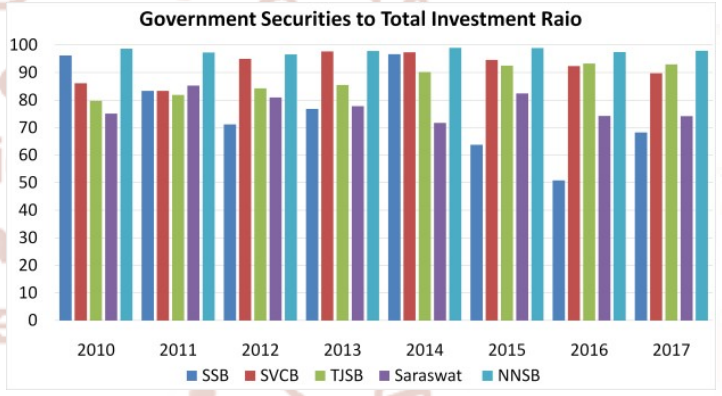

Fig: 1(d) Government Securities to Total Investment Ratio

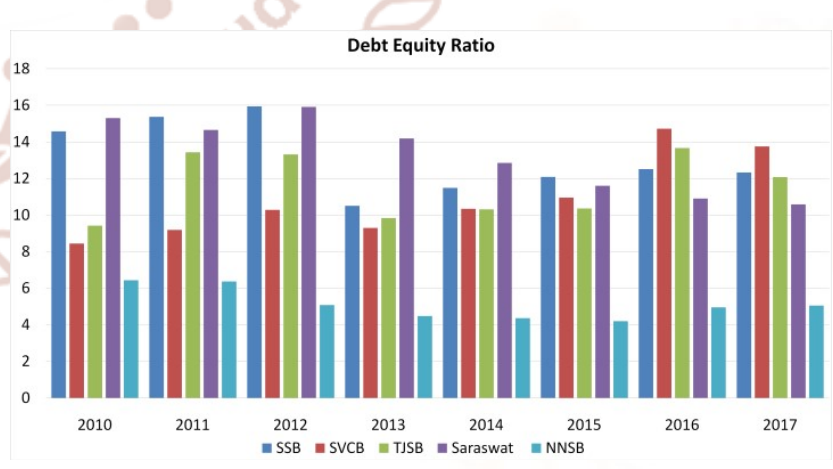

Fig: 1(e) Debt Equity Ratio

B: Analysis and Interpretation of Assets Quality (A):

Total Investment to Total Assets Ratio:

We analyze the total investment to total asset ratio for the selected period for each bank in Fig 2a. The bank more or less maintains same level of risks 23 to 28 . We observe more deviation in the mean value for SSB 
bank as compared to others. The average value of this ratio in all the banks is 26.4 .

\section{Gross NPA to Net Advance Ratio:}

The ratio as analyzed in Fig $2 b$ indicates the NNSB shows lowest 1.3 value while Saraswat bank show highest value of 3.9 for the selected period. The lower value of this ratio indicates the quality of advances in NNSB is better. The overall performance of this parameter in all banks has value 2.8 , which indicates fair performance by all.

\section{Net NPA to Net Advance Ratio:}

The ratio gives better picture of performance than Gross NPA to Net Advance Ratio. Fig 2c gives the performance of this parameter lies near 0.52 except SVCB which has slightly higher average value of 1.34 .

\section{Net NPA to Total Assets Ratio:}

This ratio also indicates the quality of advances, indicating its credit risk. The NNSB and SSB maintain this ratio to average of 0.06 and 0.02 respectively. Only TJSB maintains the ratio above 2 .

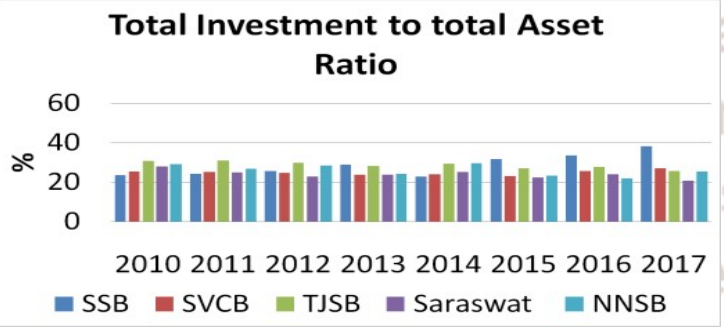

Fig: 2(a) Total Investment to Total Asset Ratio

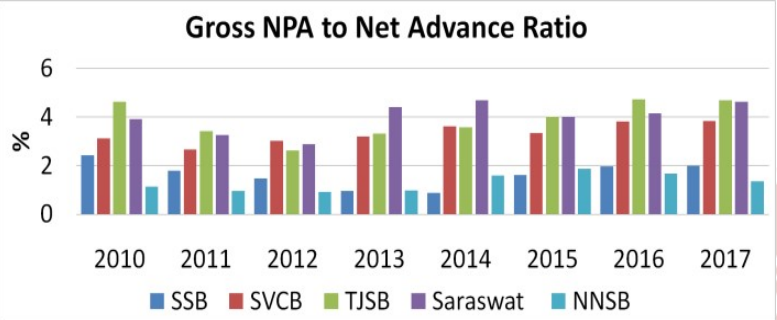

Fig: 2(b) Gross NPA to Net Advance Ratio

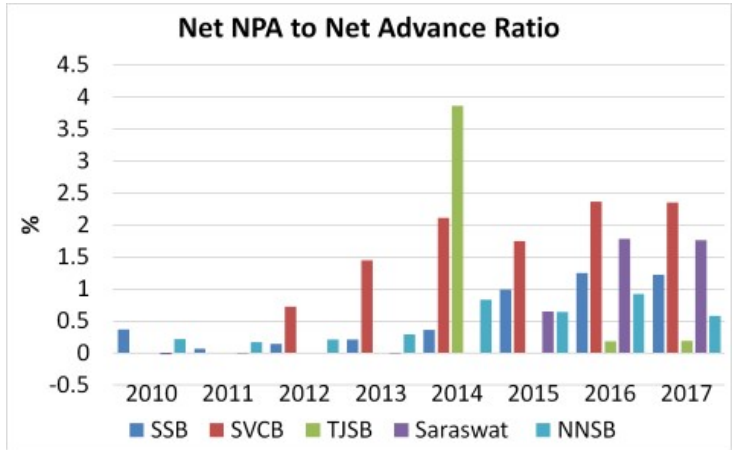

Fig: 2(c) Net NPA to Net Advance Ratio

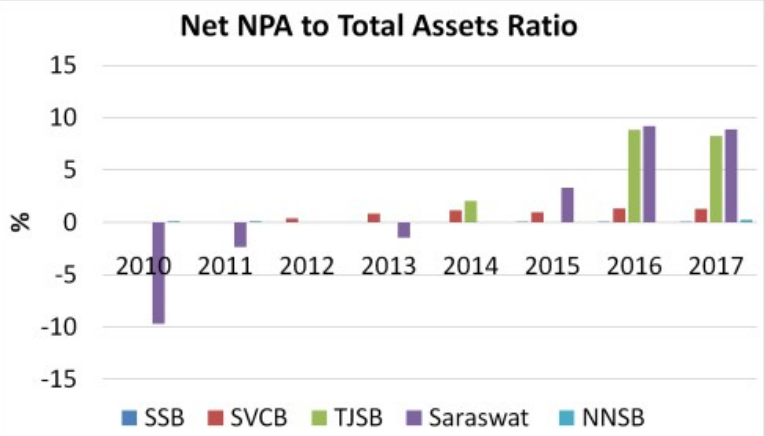

Fig: 2(d) Net NPA to Total Assets Ratio

\section{C: Analysis and Interpretation of Management efficiency test $(M)$ :}

\section{Business per employee ratio:}

The ratio indicates how much business per employee is earned by the bank. Higher ratio indicates efficient employees. We analyze the rating for the selected period and found the TJSB has best Business per employee ratio. There is a huge deviation in the values of this ratio observed for different banks. SSB and NNSB has lowest of 25 and 31 however TJSB has this average value at 90 . The quantity standard deviation for the TJSB is highest amongst all other banks, the business values also indicates the progress in the business of this bank form the period 2010 to 2017.

\section{Business per Branch Ratio:}

The ratio indicates the productivity of bank per branch. We analyze this ratio for the selected period to assess the performance of each bank. We observed per branch business in TJSB is more as compare to the other banks. This ratio matches with the figures calculated for business per employee ratio.

\section{Profit Per Branch Ratio and Profit Per Employee} Ratio:

The ratio indicates the bank performance per branch and per employee. TJSB performs best in both the ratios as compare to other branches. The standard deviation in NNSB is highest indicating more ups and downs in the profit per branch values.

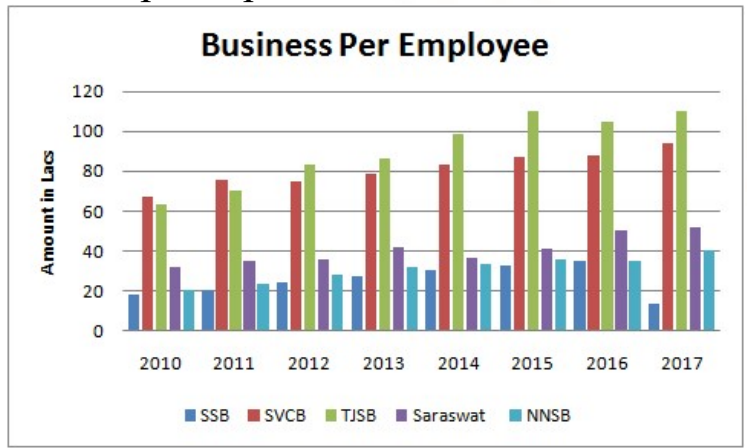

Fig: 3(a) Business Per Employee Ratio 


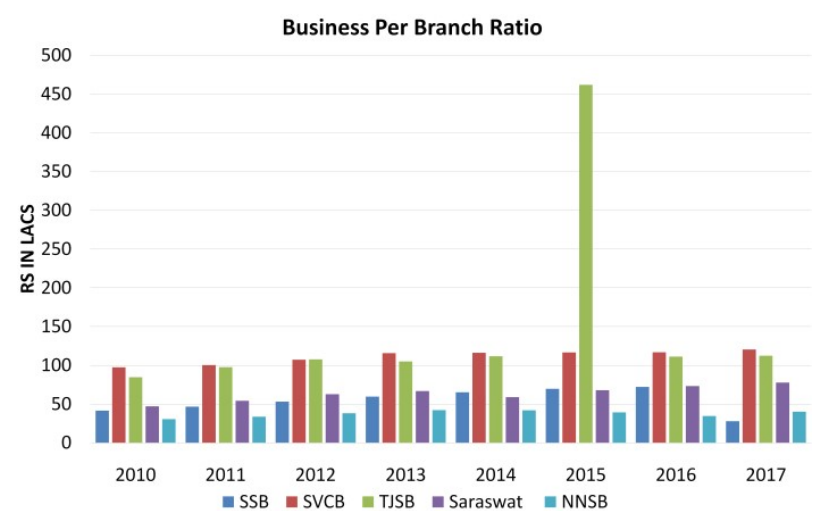

Fig: 3(b) Business per Branch Ratio

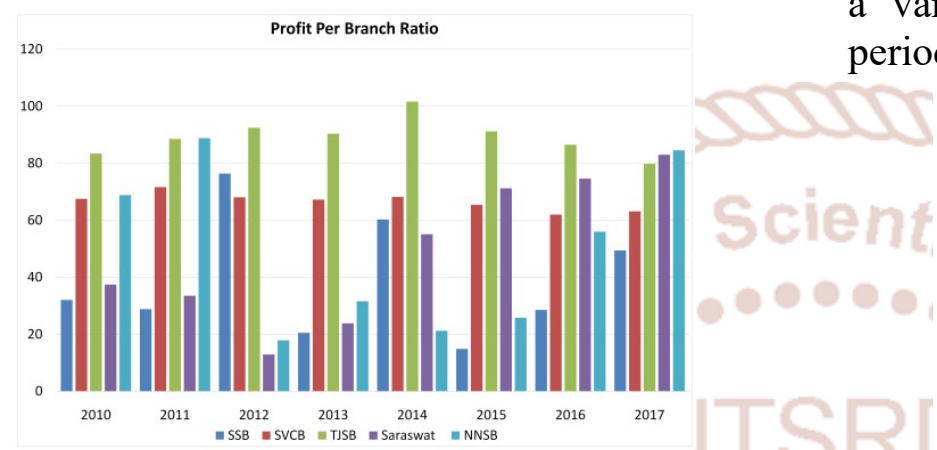

Fig: 3(c) Profit Per Branch

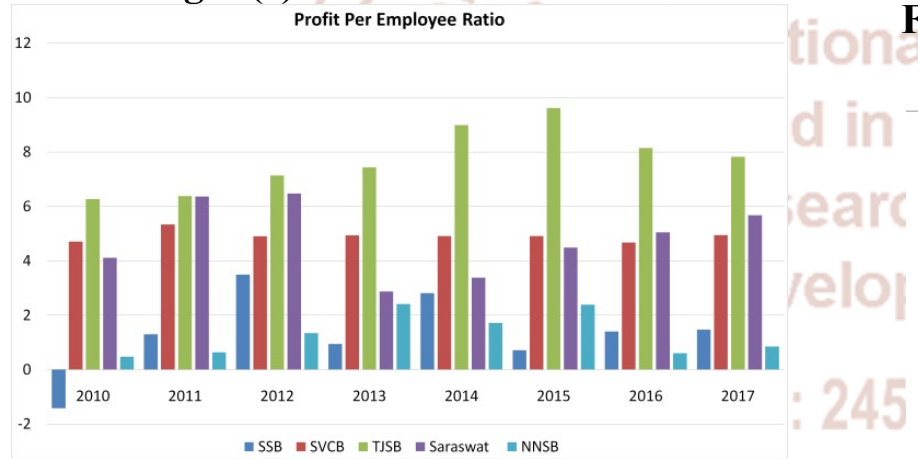

Fig: 3(d) Profit Per Employee Ratio
The quantities indicate the utilization of working fund for generation of profit. TJSB shows proper utilization of the assets ultimately driving the best operating profit and returns as compare to other banks. It also shows lowest standard deviation in the values for the above ratios over the period of time, indicating a constant performance.

\section{Interest Income To Total Assets Ratio:}

This ratio reflects the interest income generated on total assets. SSB shows highest interest income on its assets while this value is lowest for TJSB. SSB shows a variation in the interest income throughout the period. However this deviation is lowest in SVCB.

Fig: 4(a) Net Interest Margin to Total Assets Ratio
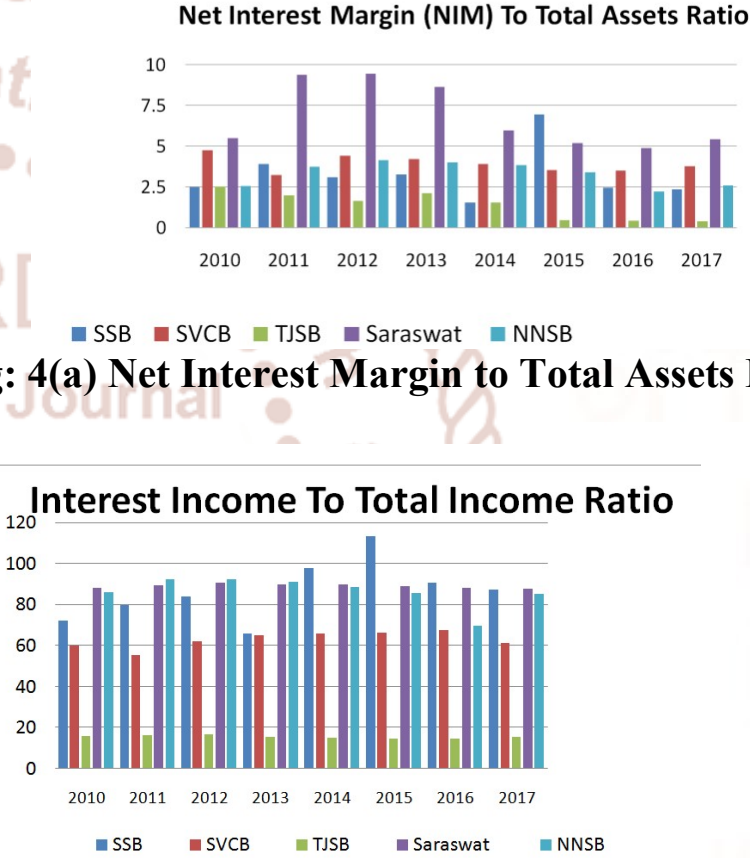

Fig: 4(b) Interest Income to Total Income Ratio

\section{Analysis and Interpretation of Efficiency Test}

(E):

Net Interest Margin to Total Assets Ratio and Interest Income To Total Income Ratio:

Net Interest Margin to Total Assets Ratio is ability of bank to keep the interest on advance high to interest on deposits. The higher value of this ratio indicates good earnings. Similarly the factor, interest earned to the total income is the basic source of earning for the banks. We analyze Saraswat Bank earns highest interest income as compare to other banks on total assets. The policies in the TJSB believe in keeping this income at moderate level.

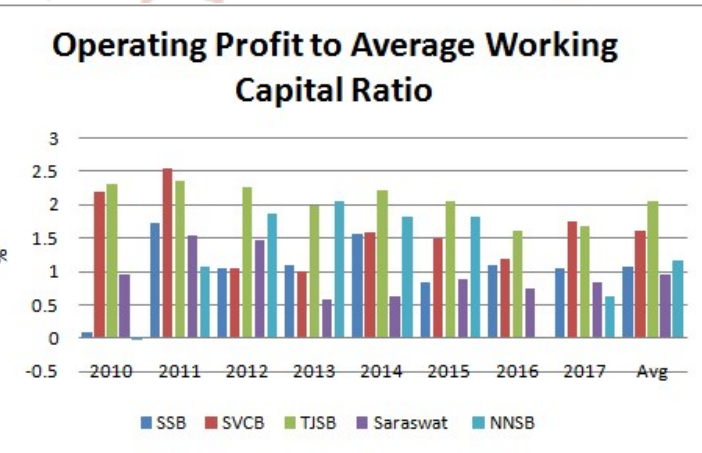

Fig: 4(c) Operating Profit to Average Working Fund Ratio Return on Assets Ratio: 
International Journal of Trend in Scientific Research and Development (IJTSRD) ISSN: 2456-6470

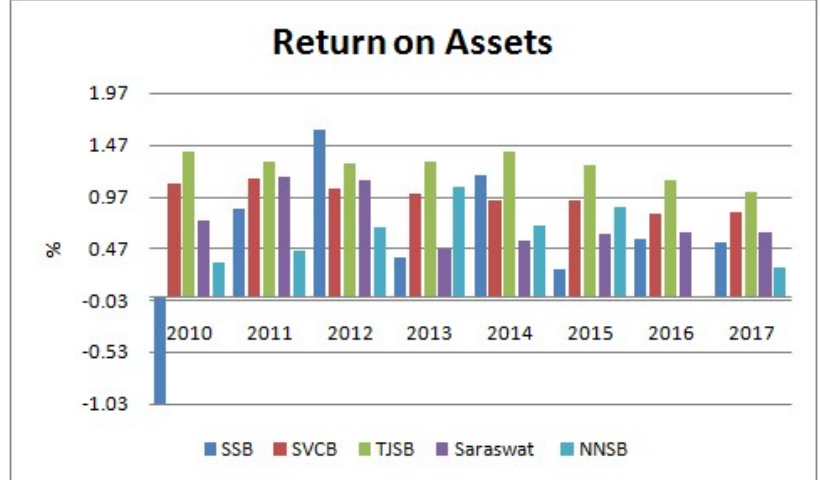

Fig: 4(d) Return on Assets Ratio

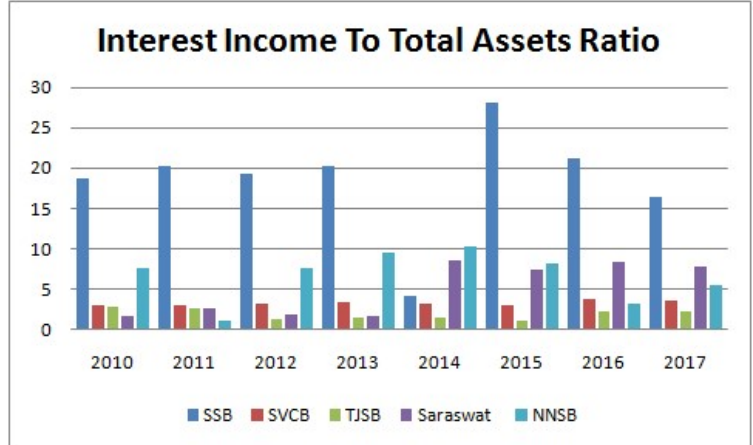

Fig: 4(e) Interest Income to Total Assets Ratio standard deviation is also high for high for NNSB, whereas Saraswat bank is at highest risk.

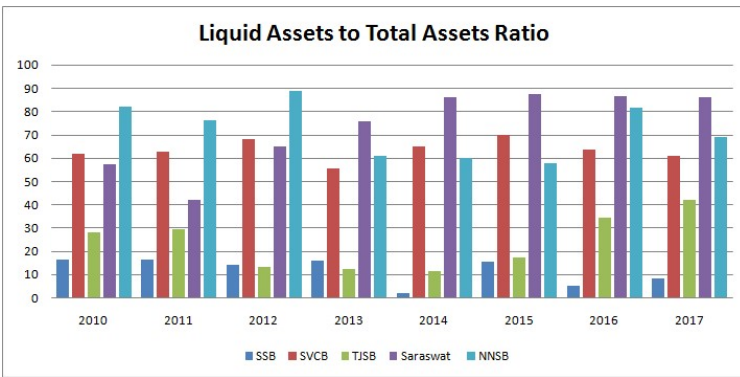

Fig: 5(a) Liquid Assets to Total Assets Ratio

E: Analysis and Interpretation of Liquidity test (L):

Liquid Assets to Total Assets Ratio and Liquid Assets to Total Deposit:

The first ratio indicates the financial and the survival ability of the banks. The low value of this ratio is hazardous for the banks. The Saraswat bank and NNSB maintain this ratio and highest values as compare to other banks. The value of standard deviation in Saraswat bank is also on higher side. The second ratio indicates liquidity available for the depositors. This ratio is also higher Saraswat bank, which indicates safe policies are practiced by Saraswat bank.

\section{Liquid Assets to Demand Deposit Ratio:}

It indicates the ability of the bank to honor its demand from deposit holders during the particular period. The higher the ratios better the liquidity. SVCB bank has highest liquid assets to demand deposit ratio.

\section{Government Securities to Total Assets Ratio:}

It indicates most liquid and safe investments. To meet banks SLR requirements they invest in government securities. It also shows higher ratio shows lower risk and safer investment. NNSB is having the highest average value of 252 and playing safe game. The

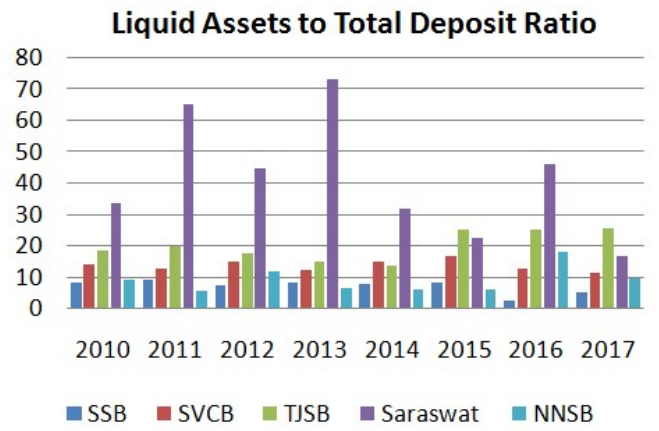

Fig: 5(b) Liquid Assets to Total Deposit Ratio

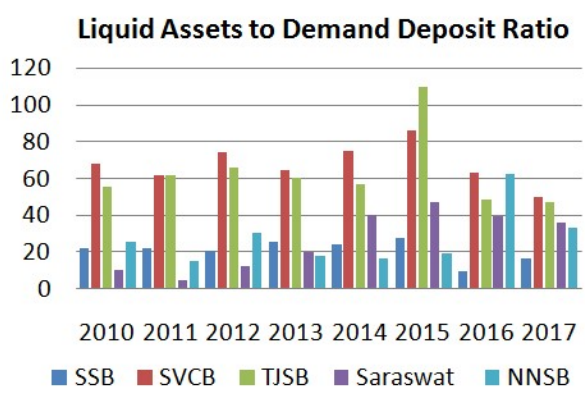

Fig: 5(c) Liquid Assets to Demand Deposit Ratio Government Security To Total Assets Ratio

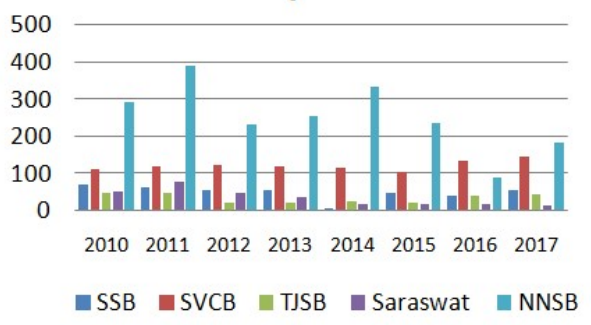

Fig: 5(d) Government Securities to Total Assets Ratio

\section{Conclusions:}

The analysis shows the performance of selected UCB over the period of 2010-2017 using CAMEL model. Each UCB is analyzed based on the values given in the Balance sheet for the CAMEL model. Our study shows the individual performances in comparison to 
the other selected UCBs of Nagpur region. The study is helpful for predicting the progress of bank and to achieve the projected goals.

Following are the observations of the study:

> The study shows that SVCB has good Capital adequacy ratio and has on higher side in $\mathrm{C}$ parameter followed by TJSB.

$>$ Further it is observed that NNSB has good Asset quality the bank is performing fair in this parameter which is followed by SSB.

$>$ TJSB has good Management Efficiency having the highest values in Management, followed by SVCB.

$>$ Further we observed that NNSB is performing good in Efficiency Test parameter which is followed by SSB.

$>$ Liquidity is well managed by SSB with the highest average values of the total rank i.e. 4.5 which is followed by NNSB.

$>$ SVCB should concentrate on Asset quality and Liquidity management

$>$ Whereas Saraswat should look into the factor of Asset Quality.

$>\mathrm{SSB}$ have to be more careful in management efficiency parameter.

$>$ TJSB is performing well in all the parameters which is followed by SSB.

\section{References:}

1) Malihe Rostami , "Camels' analysis in banking industry", Global Journal of Engineering Science and Research Management, November 2015 www.researchgate.net/publication/283854804.

2) Dash, Mihir\& Das, Annyesha.. A camels analysis of the Indian banking(2009) industry, http://ssrn.com/abstract $=1666900$

3) K.V.N Prasad \& G. Ravinder, "A camel model analysis of Nationalized Banks in India", International Journal of Trade and CommerceIIARTC January-June 2012, Volume 1, No. 1, pp. 23-33 ISSN-2277-5811. Accepted on 30/05/2012

4) Mishra Aswini Kumar, G. Sri Harsha, Shivi Anand and Neil Rajesh Dhruva, "Analyzing Soundness in Indian Banking: A CAMEL Approach" Research Journal of Management Sciences, ISSN 2319-1171 Vol.1(3), 9-14, October (2012) Res. J. Management Sci.
5) Sushendra Kumar Misra and Parvesh Kumar Aspal, "A Camel Model Analysis of State Bank Group" World Journal of Social Sciences Vol. 3. No. 4. July 2013 Issue. Pp. 36 - 55

6) S.K.Khatik, Amit Kr Nag, "Analyzing soundness of Nationalized Banks in India: a camel approach" by Applied Studies in Agribusiness and Commerce - APSTRACT Agroinform Publishing House, Budapest APSTRACT Vol. 8. Number 1. 2014

7) Dr. Srinivasan \& Yuva Priya Saminathan “ A camel model analysis of public, private and foreign sector banks in India", by, Pacific Business Review International Volume 8, Issue 9, March 2016.

8) Jagjeet Kaur, Dr. Harsh Vineet Kaur, "Camel analysis of selected public sector banks", GIAN JYOTI E-JOURNAL Volume 6, Issue 3 (JulySept 2016) ISSN 2250-348X 13th National Conference on "Management, Information Technology and Engineering".

9) "A camel model analysis of private banks in India", by Vinod Kumar and Bhawna Malhotra, EPRA International Journal of Economic and Business Review, Volume - 5, Issue- 7, July 2017, IC Value : 56.46, e-ISSN : 2347 - 9671| pISSN : 2349 - 0187, SJIF Impact Factor(2016) : 6.484, ISI Impact Factor (2013): 1.259(Dubai), UGC-Approved Journal No: 47335

10) Prof. Krupa R. Trivedi "A camel model analysis of scheduled urban co-operative bank in surat city-a case study of Surat People's Co-operative bank", by, IOSR Journal of Business and Management (IOSR-JBM), e-ISSN: 2278-487X, p-ISSN: 2319-7668 PP 48-54 Www.iosrjournals.org

11) Jaynal Uddin Ahmed "Impact of financial sector reform on the working of public sector banks: An empirical study in Barak Valleyof Assam", Department of Business Administration, Assam University, Silchar.

12) "The study of financial performance of selected public and Private sector banks in India (with reference to , CAMEL Model)"

\section{3) Website:}

https://www.rbi.org.in/scripts/PublicationReportD etails.aspx? UrlPage $=\& I D=663$; on $5^{\text {th }}$ April 5, 2018 at 4:15 pm. 